\title{
A Model-Based Economic Evaluation of Cladribine Versus Alemtuzumab, Ocrelizumab and Natalizumab for the Treatment of Relapsing-Remitting Multiple Sclerosis with High Disease Activity in Chile
}

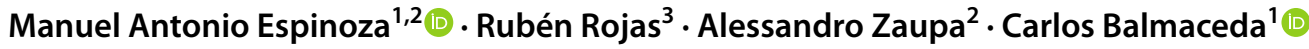

Accepted: 9 June 2021 / Published online: 5 July 2021

(C) The Author(s) 2021

\begin{abstract}
Purpose The aim of this study was to evaluate the cost effectiveness of cladribine compared with alemtuzumab, natalizumab, and ocrelizumab for the treatment of highly active multiple sclerosis (HAD-MS) from the perspective of the Chilean health care public sector.

Materials and Methods A Markov model was used to compare costs and quality-adjusted life-years (QALYs) over a 45-year time horizon using a 3\% discount rate for costs and outcomes. Natural history of the disease was modeled in terms of progression of disability according to the Expanded Disability Status Scale (EDSS). A network meta-analysis was used as a source of comparative effectiveness for disability progression and annual relapse rates. Differences in costs and outcomes were modeled for only 10 years due to high temporal uncertainty. Ocrelizumab was assumed to have the same efficacy as cladribine due to lack of data. Direct costs were taken from national tariffs and expressed in 2019 US dollars. Utilities for EDSS health states were obtained from the literature. Second-order uncertainty was characterized through deterministic and probabilistic sensitivity analysis.

Findings Compared with natalizumab (the current strategy covered in Chile), cladribine is associated with incremental costs and QALYs of US $\$ 70,989$ and 1.875, respectively (incremental cost-effectiveness ratio [ICER] \$37,861). Ocrelizumab was extendedly dominated by cladribine and natalizumab, and alemtuzumab was dominated by cladribine. A scenario analysis of a $10 \%$ discount did not modify the results substantially, but showed a decrease in the ICER of cladribine versus natalizumab (ICER \$29,833/QALY).

Implications Cladribine is a new oral alternative to treat patients with HAD-MS that is expected to produce higher QALYs than all evaluated alternatives. In the context of a conservative analysis, cladribine cannot be considered cost effective for the Chilean health care public sector using a 1 GDP per capita threshold. However, under reasonable discount scenarios, cladribine becomes an attractive alternative for the health system.
\end{abstract}

Carlos Balmaceda

cfbalmac@uc.cl

1 Unidad de Evaluación de Tecnologías en Salud, Centro de Investigación Clínica, Pontificia Universidad Católica de Chile, Diagonal Paraguay 362, Piso 2, Santiago, Chile

2 Departamento de Salud Pública, Pontificia Universidad Católica de Chile, Diagonal Paraguay 362, Piso 2, Santiago, Chile

3 Fractal-EDM, Santiago, Chile 


\section{Key Points for Decision Makers}

Given the increasing number of approvals in multiple sclerosis, payers might consider evaluating these new alternatives for highly active multiple sclerosis (HADMS) for coverage in a high-cost drug fund.

Our findings suggest that cladribine can be considered cost effective at threshold of 3 GDP per capita, with an estimated incremental cost-effectiveness ratio (ICER) of US\$37,861/QALY.

In July 2019, cladribine, alemtuzumab, and ocrelizumab were incorporated formally into the Ley Ricarte Soto Fund to treat HAD-MS.

Considering a $10 \%$ discount scenario, the ICER of cladribine decreased between 1 and 2 GDP per capita (US\$29,833/QALY).

\section{Introduction}

Multiple sclerosis (MS) is a chronic autoimmune disease of the central nervous system (CNS) that results in progressive inflammation of the brain and spinal cord due to demyelization and axonal degeneration [1]. The prevalence worldwide is estimated in 30 per 10,000 inhabitants, affecting mainly adults $<40$ years old, and is three times more frequent in women [2]. In Latin America, the countries most affected by MS are Brazil and Argentina, with prevalence up to 21.5 per 100,000 inhabitants, whereas Ecuador, Colombia, and Panama show 0.75-6.5 cases per 100,000 inhabitants [3]. In Chile, the prevalence of MS has been estimated in the range of 11.7-13.4 per 100,000 inhabitants, with a female to male ratio of $2: 1[4,5]$. In addition, the disease burden in Chile has been estimated to be 329 disability-adjusted lifeyears (DALYs), accounting for $1 \%$ of all neuropsychiatric diseases [6].

Generally, MS starts with a relapsing-remitting course (RRMS), characterized by acute episodes of neurological symptoms (vision loss, pain, fatigue, and impaired coordination), which are often followed by periods of remission where patients recover most of their functions, though they may maintain some deficit. Among patients with RRMS, there is a subset that show an increased rate of relapse or disability progression, usually referred as high disease activity (HAD-MS). They usually progress to a form called secondary progressive MS (SPMS) after 15-25 years, where patients present a rapid impairment with progressive neurodegeneration and disability. HAD-MS includes two subgroups: rapidly evolving severe RRMS (RES-MS), in which, according to the European Medicines Agency (EMA), patients present two or more disabling relapses in 1 year and one or more gadolinium-enhancing $(\mathrm{Gd}+)$ lesions on brain MRI, or a significant increase in T2 lesion load as compared with a previous recent MRI. The second subgroup is the sub-optimally treated (SOT-MS) patients, defined by one relapse in the previous year plus at least one $\mathrm{Gd}+$ lesion on brain MRI and nine lesions in T2. A third form of MS is called primary progressive multiple sclerosis (PPMS) and affects only $15 \%$ of cases. It is characterized by a progressive neurodegeneration and early disability from disease onset.

There is no curative treatment available for MS and the current goal of disease-modifying treatments (DMTs) is to reduce the early clinical and sub-clinical disease activity to avoid potential disability progression in the long term. To date, 15 DMT therapies have been approved by the US Food and Drug Administration (FDA) [7], all concentrated on controlling, segregating, blocking, or depleting diseasecausing autoimmune cells, thus limiting their ability to enter and damage the CNS. DMTs can be grouped in two categories: 'moderate efficacy' like $\beta$-interferons (INF, two drugs), glatiramer acetate (GA, two drugs), teriflunomide, dimethyl fumarate, and daclizumab; and 'high efficacy', which currently comprise alemtuzumab, ocrelizumab, fingolimod, and natalizumab. All these therapies have shown significant results compared with placebo in terms of reducing relapse events and disease progression as demonstrated by clinical and MRI activity. Nevertheless, 'high efficacy' agents have the potential for more serious adverse effects or have a less well established safety profile and are usually reserved for HAD-MS [8].

Cladribine, (2-chloro-2'-deoxyadenosine) is an immunomodulator acting through its active metabolite, 2-chlorodeoxyadenosine triphosphate, which causes inhibition of the synthesis and repair of DNA, leading to cellular apoptosis. Consequently, a rapid and sustained depletion of the CD4+ and CD8+ lymphocytes population is observed as well as a transitory reduction of CD19+ B leucocytes. Originally approved by the FDA as a treatment for hairy cell leukemia, cladribine efficacy and safety for treatment of RRMS was evaluated in a phase III clinical study, named CLARITY (cladribine tablets treating MS orally) $[9,10]$ and its extension (CLARITY EXT) [11]. A total of 1326 patients with RRMS were randomly assigned in an approximate 1:1:1 ratio to receive one of two cumulative doses of cladribine tablets (either $3.5 \mathrm{mg}$ or $5.25 \mathrm{mg}$ per kilogram of body weight) or matching placebo. It was concluded that cladribine $(3.5 \mathrm{mg} / \mathrm{kg})$ was associated with a statistically significant improvement in annualized relapse rate (ARR) and a lower proportion of relapsing patients compared with placebo, and this effect was not different for the $5.25-\mathrm{mg} / \mathrm{kg}$ group. 
A further analysis of the clinical evidence showed a significant effect on the disability progression restricted to the HAD-MS subpopulation. In addition, CLARITY EXT indicated that treatment with cladribine over 2 years $(3.5 \mathrm{mg} /$ $\mathrm{kg}$ ), followed by 2 years of placebo, was not significantly different to continuous treatment [11]. This finding suggests that cladribine might present an interesting economic performance compared with other alternatives on the market. In terms of safety, cladribine showed a good risk profile including its use in pregnant women.

The aim of this study was to estimate the cost effectiveness of cladribine compared with natalizumab, ocrelizumab, and alemtuzumab for the treatment of patients with HADMS from the perspective of the Chilean health care public sector.

\section{Methods}

\subsection{Model Design}

A Markov state transition model was used to predict the lifetime costs and benefits of treatment with cladribine and its comparators. The model uses the Kurtzke Expanded Disability Status Scale (EDSS) to define the disability status of people with MS, which comprises 10 health states plus a separate one for death (Fig. 1) [12].

At model entry, the cohort was proportionally assigned to the 10 EDSS states according to the baseline EDSS distribution of the CLARITY study (Table 1), an assumption that was tested and validated with local experts [9-11]. We implemented annual cycles to model progression of disease over a 45-year time horizon in the base case, which is a lifetime horizon. In each cycle, patients were at risk of either moving to a higher EDSS state (disability progression), moving to a lower EDSS state (improvement in disability status), remaining at their current level of disability, or dying. In addition, occurrence of relapses and discontinuation of treatment were also captured in the model. To estimate the number of relapses we multiplied the ARR by the number of patients alive in each cycle. Reasons for treatment discontinuation were loss of DMT efficacy, loss of tolerability, or development of SPMS (EDSS > 7).

Transition probabilities were obtained from the British Columbia registry $[13,14]$ and were assumed to be constant throughout the time horizon. A half-cycle correction was applied to every transition probability. These probabilities were calculated for a cohort of people with active RRMS, including persons with less active forms of RRMS than HAD-MS. Therefore, in order to adjust these parameters to the HAD-MS population, we used an acceleration factor (AF) to account for the expected larger probability of EDSS progression. The correction was applied to EDSS states 0-5



DMT: Disease Modifying Therapies; EDSS: Expanded Disability Status Scale; SPMS: Secondary-progressive multiple sclerosis

Fig. 1 Structure of the 11-state EDSS model considering periods on and off DMT used in the Markov models ** Source: Technology appraisal provided by Merck

only, whereas for patients who develop SPMS or EDSS $\geq 6$, the transition probabilities are expected to be similar to the general RRMS group. The adjustment factor was calculated as the hazard ratio of progression rates in HAD-MS vs nonHAD-MS patients in the placebo arm of CLARITY at week 96, which produced an estimate of 1.382. Although this approximation has been criticized elsewhere [12] because it assumes a constant effect, possibly underestimating the progression rate, we decided to maintain this assumption since no additional data to produce better estimates were available.

Although CLARITY EXT demonstrated that the cladribine effect would persist in years 3 and 4 and some patients did not report relapses in years 5 and 6 , it is still uncertain when a further medication cycle is necessary. Hence, we 
Table 1 Model inputs: non-cost parameters such as general settings, efficacy inputs, probabilities of adverse events, and utilities used in the base-case model

\begin{tabular}{|c|c|c|c|}
\hline Parameter & Value (SE) & Distribution & Source \\
\hline Average starting age & $38.7(0.473)$ & Log-normal & CLARITY study [9] \\
\hline Female/male ratio & 1.93 & N/A & CLARITY study [9] \\
\hline Average patient weight & $70.67(3.46)$ & Normal & NHS 2010 [19] \\
\hline \multicolumn{4}{|c|}{ Annualized rate of relapse by EDSS state } \\
\hline EDSS 0 & $0.890(0.267)$ & Log-normal & \multirow[t]{10}{*}{ NICE [38] } \\
\hline EDSS 1 & $0.679(0.204)$ & Log-normal & \\
\hline EDSS 2 & $0.642(0.193)$ & Log-normal & \\
\hline EDSS 3 & $0.596(0.179)$ & Log-normal & \\
\hline EDSS 4 & $0.523(0.157)$ & Log-normal & \\
\hline EDSS 5 & $0.458(0.137)$ & Log-normal & \\
\hline EDSS 6 & $0.401(0.120)$ & Log-normal & \\
\hline EDSS 7 & $0.310(0.093)$ & Log-normal & \\
\hline EDSS 8 & $0.251(0.075)$ & Log-normal & \\
\hline EDSS 9 & $0.217(0.065)$ & Log-normal & \\
\hline \multicolumn{4}{|l|}{ Baseline EDSS distribution } \\
\hline EDSS 0 & $2.80 \%$ & Dirichlet & \multirow[t]{10}{*}{ CLARITY study [9] } \\
\hline EDSS 1 & $2.80 \%$ & Dirichlet & \\
\hline EDSS 2 & $32.50 \%$ & Dirichlet & \\
\hline EDSS 3 & $21.50 \%$ & Dirichlet & \\
\hline EDSS 4 & $23.50 \%$ & Dirichlet & \\
\hline EDSS 5 & $11.10 \%$ & Dirichlet & \\
\hline EDSS 6 & $5.80 \%$ & Dirichlet & \\
\hline EDSS 7 & $0.00 \%$ & Dirichlet & \\
\hline EDSS 8 & $0.00 \%$ & Dirichlet & \\
\hline EDSS 9 & $0.00 \%$ & Dirichlet & \\
\hline \multicolumn{4}{|l|}{ Mortality multiplier } \\
\hline EDSS 0 & 1.00 & Log-normal & \multirow[t]{10}{*}{ Sadovnik et al. [39] } \\
\hline EDSS 1 & 1.43 & Log-normal & \\
\hline EDSS 2-2.5 & 1.60 & Log-normal & \\
\hline EDSS 3-3.5 & 1.64 & Log-normal & \\
\hline EDSS 4-4.5 & 1.67 & Log-normal & \\
\hline EDSS 5-5.5 & 1.84 & Log-normal & \\
\hline EDSS 6-6.5 & 2.27 & Log-normal & \\
\hline EDSS 7-7.5 & 3.10 & Log-normal & \\
\hline EDSS 8-8.5 & 4.45 & Log-normal & \\
\hline EDSS 9-9.5 & 6.45 & Log-normal & \\
\hline \multicolumn{4}{|c|}{ Disability progression (hazard ratio versus placebo) } \\
\hline Cladribine & $0.180(0.176)$ & Log-normal & \multirow[t]{4}{*}{ NMA Merck [40] } \\
\hline Alemtuzumab & $0.360(0.132)$ & Log-normal & \\
\hline Natalizumab & $0.353(0.139)$ & Log-normal & \\
\hline Ocrelizumab & $0.180(0.176)$ & Log-normal & \\
\hline \multicolumn{4}{|c|}{ Acute relapse events (rate ratio versus placebo) } \\
\hline Cladribine & $0.350(0.056)$ & Log-normal & \multirow[t]{4}{*}{ NMA Merck [40] } \\
\hline Alemtuzumab & $0.353(0.034)$ & Log-normal & \\
\hline Natalizumab & $0.399(0.031)$ & Log-normal & \\
\hline Ocrelizumab & $0.366(0.040)$ & Log-normal & \\
\hline Recue therapy (only for cladribine) & $0.400(0.076)$ & Log-normal & CLARITY study [9] \\
\hline
\end{tabular}


Table 1 (continued)

\begin{tabular}{llll}
\hline Parameter & Value $(\mathrm{SE})$ & Distribution & Source \\
\hline Treatment waning effect & & & NICE assumption [12] \\
0-2 years & 1.000 & N/A & N/A \\
2-4 years & 0.750 & N/A & \\
4-10+ years & 0.500 & & \\
\hline
\end{tabular}

Annual probability of $\mathrm{CLA}^{1} \mathrm{ALE}^{1} \mathrm{NAT}^{2} \mathrm{OCR}^{3}$ Dist Source

treatment withdrawal

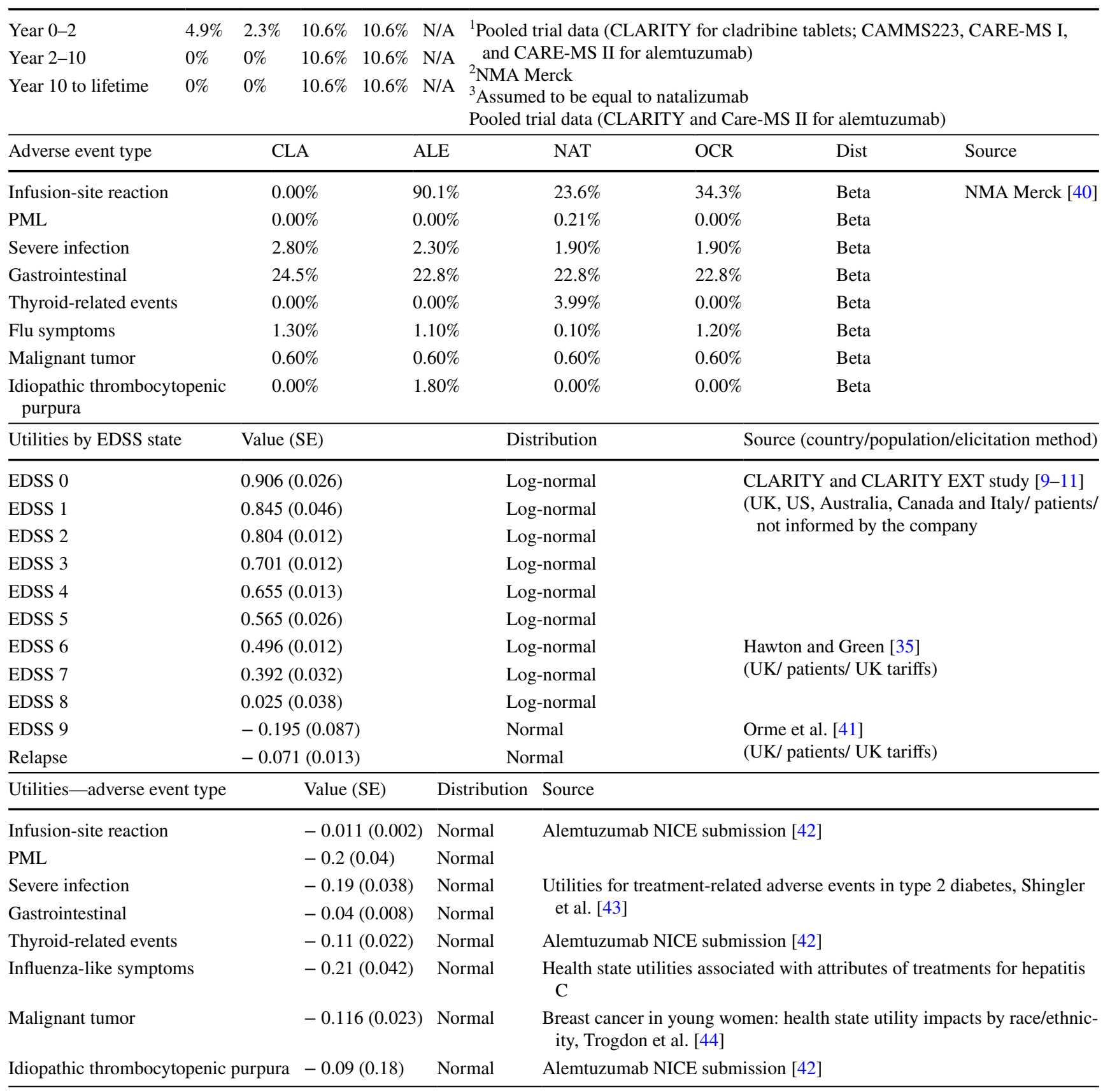

$A L E$ alemtuzumab, $C L A$ cladribine, Dist distribution, N/A not applicable, NAT natalizumab, $O C R$ ocrelizumab, $P M L$ progressive multifocal leukoencephalopathy, $S E$ standard error 
adopted a conservative approach, applying a further cycle of the drug at years 5 and 6 followed by the same pattern of no treatment in the subsequent 2 years.

The model also incorporated a waning effect, which gradually reduced the treatment effect beyond the second year according to previous NICE appraisals for MS [15, 16]. For all comparators, we assumed $100 \%$ of effect in years 1 and $2,75 \%$ in years 3 and 4 , and 50\% thereafter. This approach for cladribine may lead to a sub-estimation of the drug effect compared with other alternatives, as the CLARITY EXT study has shown a persistent effect of cladribine in years 3 and 4 compared with placebo. However, the absence of relapses was observed in $75 \%$ of the cases, which is consistent with our assumption [11].

The model has been undergoing face validity, verification, and validation consistent with recommendations by ISPOR Task Force 7 [17]; nonetheless, external validation and predictive validation were not feasible to perform.

\subsection{Target Population}

Patients with HAD-RRMS, including rapidly evolving severe (RES) and high relapse activity types, as described in post-hoc analysis of the CLARITY study $(n=261)$, were followed through the Markov model [9, 10, 18]. HADRRMS was the most effective subgroup of the post-hoc analysis, and therefore, in order to make the most of cladribine's potential, HAD-RRMS patients were defined as the target population for this study. The definition of HAD-RRMS used in this study was any patients with $\geq 2$ relapses during the year prior, whether on DMT treatment or not. The starting age was the mean age of the trial: $37.9 \pm 10.3$ years [9]. The proportion of women with the health problem that was used to estimate the weighted mortality rate dependent on female/male ratio comes from the trial (68.8\% females), whilst the weights for both genders are from the National Health Survey 2010 (average weight $70.67 \mathrm{~kg}$ ) [19].

\subsection{Comparators}

Primarily, cladribine was compared with placebo, as in the CLARITY study. The Chilean clinical guidelines for MS did not mention treatment schemes for HAD-MS [6, 20]. Therefore, the comparators' selection was guided by Chilean leading clinicians' suggestions, owing to their potential effectiveness in HAD-MS patients and according to the approved indications of the local regulatory authority. Consequently, comparators were limited only to natalizumab, ocrelizumab, and alemtuzumab. The selection of each comparator was validated by local clinical experts and an advisor of the Ministry of Health in Chile [21]. Information about the treatment regimen is presented in Table 2.

\subsection{Comparative Efficacy}

Treatment effect estimates were obtained from a network meta-analysis (NMA) [22], which provided effectiveness estimates for cladribine versus alemtuzumab and natalizumab. The comparison against ocrelizumab was not reported due to lack of data. Using a conservative approach, we supposed an efficacy for ocrelizumab equivalent to cladribine. The selected ratio estimates are summarized in Table 1.

Although we modeled a 45-year time horizon, comparative effectiveness and drug costs were modeled only for 10 years. In other words, after year 10, we assumed that all patients would receive one drug, incurring the same costs and producing the same effects. There are several reasons to support this assumption. First, there is large uncertainty on whether the treatment effect holds after 6 years. In fact, most studies model a waning effect assuming $50 \%$ of the effect after year 5. However, there is no information to estimate what is expected after year 10 with these new drugs. Second, it is highly likely that the differences in costs will be different in 10 years, given a change in the market of treatments for MS. Third, this approach is better than modeling a 10-year time horizon, because the effect on therapies observed in the first 10 years will affect the natural progression of the disease in the remaining years, even though patients are forced to receive one single treatment. This will impact on the cost and QALY estimates. We implemented these assumptions by applying the effect reported for natalizumab (the actual drug coverage in Chile). For costs, we assumed the average price among the four comparators included in this report.

Table 2 Treatment regimens for each comparator (doses, posology, number of doses per year, and duration)

\begin{tabular}{|c|c|c|c|c|}
\hline Technology & Dose & Posology & Number of doses per year & Duration \\
\hline Cladribine & $0.875 \mathrm{mg} / \mathrm{kg}$ per dose & $10 \mathrm{mg}$ every day for 2 weeks/year & 12 tabs per year & 2 years \\
\hline Alemtuzumab & $12 \mathrm{mg}$ per day & $\begin{array}{l}12 \mathrm{mg} / \text { day for } 5 \text { days (1st year) } \\
12 \mathrm{mg} / \text { day for } 3 \text { days ( } 2 \mathrm{nd} \text { year) }\end{array}$ & $\begin{array}{l}5 \text { per year ( } 1 \text { st year) } \\
3 \text { per year ( } 2 \text { nd year) }\end{array}$ & 2 years \\
\hline Natalizumab & $300 \mathrm{mg}$ per dose & $300 \mathrm{mg}$ every 4 weeks & 13 per year & Lifetime \\
\hline Ocrelizumab & $300 \mathrm{mg}$ per dose & $\begin{array}{l}300 \mathrm{mg} \text { every } 2 \text { weeks (initial dose) } \\
600 \mathrm{mg} \text { every } 6 \text { months (maintenance dose) }\end{array}$ & $\begin{array}{l}6 \text { per year ( } 1 \text { year }) \\
4 \text { per year }(2+\text { years })\end{array}$ & Lifetime \\
\hline
\end{tabular}




\subsection{Cost Input}

The total cost of each intervention comprised six components: drug acquisition, drug administration, treatment and disease follow-up, drug monitoring, adverse events, and relapses (Table 3). Costs were measured from the perspective of the public health sector in Chilean pesos (CLP) (adjusted to 2018 using the consumer price index) and then converted to US dollars ( $1 \mathrm{USD}=667 \mathrm{CLP})$. The study followed the Chilean guidelines for economic evaluation provided by the Ministry of Health [23]. The valuation of resources was performed using the 2018 FONASA
Table 3 Model inputs: cost parameters such as drug acquisition, drug administration, clinical management, relapse event, drug monitoring, and event adverse used in the basecase model

\begin{tabular}{|c|c|c|c|}
\hline Parameter & Value $(\mathrm{SE})^{\mathrm{a}}$ & Distribution & Source \\
\hline \multicolumn{4}{|l|}{ Drug acquisition } \\
\hline Cladribine & $\$ 2547$ & N/A & \multirow{4}{*}{$\begin{array}{l}\text { Merck Chile [40] } \\
\text { MINSAL [45] }\end{array}$} \\
\hline Alemtuzumab & $\$ 8250$ & N/A & \\
\hline Natalizumab & $\$ 2320$ & N/A & \\
\hline Ocrelizumab & $\$ 5411$ & N/A & \\
\hline \multicolumn{4}{|c|}{ Clinical Management by EDSS state (Annualized cost) } \\
\hline EDSS 0 & $\$ 403(\$ 40)$ & Gamma & \multirow{10}{*}{$\begin{array}{l}\text { Own elaboration with } \\
\text { clinical expert and } \\
\text { using EVC } 2015 \\
\text { tariffs [46] }\end{array}$} \\
\hline EDSS 1 & $\$ 403(\$ 40)$ & Gamma & \\
\hline EDSS 2 & $\$ 403(\$ 40)$ & Gamma & \\
\hline EDSS 3 & $\$ 403(\$ 40)$ & Gamma & \\
\hline EDSS 4 & $\$ 403(\$ 40)$ & Gamma & \\
\hline EDSS 5 & $\$ 403(\$ 40)$ & Gamma & \\
\hline EDSS 6 & $\$ 987(\$ 99)$ & Gamma & \\
\hline EDSS 7 & $\$ 987(\$ 99)$ & Gamma & \\
\hline EDSS 8 & $\$ 987$ (\$99) & Gamma & \\
\hline EDSS 9 & $\$ 987(\$ 99)$ & Gamma & \\
\hline Drug administration & $\$ 218$ & Point estimate & \\
\hline \multicolumn{4}{|l|}{ Relapse event } \\
\hline With hospitalization & $\$ 1258( \pm 10 \%)$ & Gamma & \multirow[t]{2}{*}{ EVC 2015 [46] } \\
\hline w/o hospitalization & $\$ 564( \pm 10 \%)$ & Gamma & \\
\hline \multicolumn{4}{|l|}{ Drug monitoring } \\
\hline Biochemistry test & $\$ 10$ & Point estimate & \multirow[t]{2}{*}{ EVC 2015 [46] } \\
\hline Complete blood counts & $\$ 8$ & Point estimate & \\
\hline HVP test & $\$ 81$ & Point estimate & UC-FONASA 2017 \\
\hline MRI scan & $\$ 98$ & Point estimate & \multirow[t]{4}{*}{ EVC 2015 [46] } \\
\hline Neurology visit & $\$ 14$ & Point estimate & \\
\hline Ophthalmology visit & $\$ 14$ & Point estimate & \\
\hline Thyroid function test & $\$ 14$ & Point estimate & \\
\hline Tuberculin skin test & $\$ 7$ & Point estimate & MAI 2018 [24] \\
\hline Urinalysis test with microscopy & $\$ 2$ & Point estimate & EVC 2015 [46] \\
\hline $\mathrm{JC}$ virus test & $\$ 99$ & Point estimate & UC-FONASA 2017 \\
\hline \multicolumn{4}{|l|}{ Adverse event type } \\
\hline Infusion site reaction & & N/A & \multirow{8}{*}{$\begin{array}{l}\text { Own elaboration with } \\
\text { clinical expert and } \\
\text { using EVC } 2015 \\
\text { tariffs [46] }\end{array}$} \\
\hline PML & $\$ 999(\$ 100)$ & Gamma & \\
\hline Severe infection & $\$ 841(\$ 84)$ & Gamma & \\
\hline Gastrointestinal & $\$ 107(\$ 11)$ & Gamma & \\
\hline Thyroid-related events & $\$ 75(\$ 8)$ & Gamma & \\
\hline Influenza-like symptoms & $\$ 24(\$ 2)$ & Gamma & \\
\hline Malignant tumor & $\$ 5380(\$ 538)$ & Gamma & \\
\hline Idiopathic thrombocytopenic purpura & \$1124 (\$112) & Gamma & \\
\hline
\end{tabular}

${ }^{\mathrm{a}}$ Unitary costs in US dollars

HVP human papillomavirus, JC John Cunningham, MRI magnetic resonance imaging, N/A not applicable, $P M L$ progressive multifocal leukoencephalopathy 
(national public insurer) tariff for public provision of health services (Modalidad de Atención Institucional, MAI) [24]. Prices of treatment comparators were obtained from health technology assessment documents produced by the Ministry of Health in 2017. For cladribine, we assumed a price consistent with 12.4 tablets per year. This was estimated based on an average body weight of $70.67 \mathrm{~kg}$, which was calculated according to the data provided by the 2010 Chilean national health survey [19].

Administration costs included neurological visits, nurse intervention, chlorphenamine, acetaminophen, acyclovir, and methylprednisolone. Resource use was estimated based on the information provided by two rheumatologists from 'Red Salud UC-Christus' via individual interviews. Likewise, costs associated with relapse events were estimated based on packages of services built using information from local experts. We estimated an expected cost for relapse necessitating hospitalization and out-of-hospital care. Furthermore, we estimated expected costs due to treatment and follow-up for EDSS states, assuming the same cost for EDSS 0-5, increasing for EDSS states 6-9 to account for rehabilitation therapies. For cost of treatment-related adverse events, we built packages of services including all events reported in the literature for one or more comparators included in this study [22, 25-28].

\subsection{Utilities}

Utilities used for the calculation of quality-adjusted lifeyears (QALYs) were taken from previous reports validated by NICE committees [29]. Details of utilities and disutilities associated with each EDSS state and adverse event are reported in Table 1.

\subsection{Time Horizon, Discounting and Thresholds}

A 45-year time horizon was used to approach a lifetime horizon, with a starting age of 37.9. The cost and benefits were discounted using an undifferentiated $3 \%$ discount rate with $0 \%$ and $6 \%$ used in scenarios, in accordance with the Chilean guideline for health economic evaluation [23]. The thresholds used in this study were 1 and 3 GDP per capita, as mentioned in the Chilean guideline for health economic evaluation [23].

\subsection{Sensitivity Analysis}

Deterministic and probabilistic sensitivity analyses (PSA) were performed to characterize second-order uncertainty. In the one-way deterministic sensitivity analysis, we varied each parameter, increasing and decreasing the magnitude of their point estimates using their confidence interval. Discount rate parameters (cost and benefits) were sensitized between $0 \%$ and $6 \%$, whilst the "basal male/female" parameter, and the "discontinuation natalizumab and cladribine" parameter were varied by $25 \%$ relative. For PSA, we ran 10,000 Monte Carlo simulations using the corresponding a priori distributions presented in Tables 1 and 3 .

\section{Results}

\subsection{Base Case Results}

Results of the base-case cost-effectiveness analysis are shown in Table 4. Compared with natalizumab, none of the alternatives can be considered cost effective when the
Table 4 Result of base-case cost-utility analysis and hypothetical introduction of a $10 \%$ price discount

\begin{tabular}{llrlll}
\hline Treatment & Total cost (US\$) & QALYs & ICER & ICER vs NTZ & \\
\hline Natalizumab & $\$ 218,959$ & 9.519 & $\$ 0$ & $\$ 0$ & \\
Ocrelizumab & $\$ 241,778$ & 9.912 & $\$ 58,062$ & $\$ 58,062$ & Extended dominated \\
Cladribine & $\$ 289,949$ & 11.394 & $\$ 32,504$ & $\$ 37,861$ & \\
Alemtuzumab & $\$ 293,629$ & 10.786 & $-\$ 6052$ & $\$ 58,934$ & Dominated by CLB \\
$\begin{array}{lllll}\text { 10\% price discount } \\
\text { Natalizumab }\end{array}$ & $\$ 218,959$ & 9.519 & $\$ 0$ & & \\
Ocrelizumab & $\$ 241,778$ & 9.912 & $\$ 58,062$ & $\$ 58,062$ & Extended dominated \\
Cladribine & $\$ 274,898$ & 11.394 & $\$ 22,348$ & $\$ 29,833$ & \\
Alemtuzumab & $\$ 293,629$ & 10.786 & $-\$ 30,807$ & $\$ 58,934$ & Dominated by CLB \\
Sensitivity analysis: $10-$ year time horizon & & & & \\
Alemtuzumab & $\$ 140,654$ & 5.026 & $\$ 0$ & $\$ 160,964$ & \\
Cladribine & $\$ 153,795$ & 5.212 & $\$ 70,745$ & Dominant & \\
Natalizumab & $\$ 170,109$ & 5.209 & $-\$ 5,907,228$ & $\$ 0$ & Dominated by CLB \\
Ocrelizumab & $\$ 191,421$ & 5.446 & $\$ 90,125$ & $\$ 90,125$ & \\
\hline
\end{tabular}

$C L B$ cladribine, ICER incremental cost-effectiveness ratio, $N T Z$ natalizumab, $Q A L Y S$ quality-adjusted lifeyears 
incremental cost-effectiveness ratios (ICERs) are compared to the Chilean reference threshold (1 GDP per capita $=$ US\$15,750). However, cladribine shows the best costeffectiveness profile being the only alternative whose ICER is $<3 \times$ GDP, often used in many jurisdictions as a higher threshold. Table 4 also shows a scenario analysis where we assumed a hypothetical $10 \%$ discount in the price of cladribine. Nevertheless, no significant changes in cladribine performance concerning its comparators were observed. Figure 2 illustrates the results on the cost-effectiveness plane.

\subsection{Deterministic Sensitivity Analysis Results}

Figure 3 presents the set of parameters that showed the largest impact on cost effectiveness. It is worth noting that the diagram shows changes in terms of incremental net health benefits (iNHB), which for the base-case comparison between cladribine and natalizumab corresponds to -1.06 NHB. These results show that the main impact was related to variation in the discounting rate applied to costs; the probability to suspend natalizumab in the first 2 years or between 2 and 10 years; and basal weight of the intent-to-treat population. Nevertheless, no parameter produced significant changes on a decision based on cost effectiveness when a cost-effectiveness threshold of US\$15,750 was assumed.

\subsection{Probabilistic Sensitivity Analysis Results}

The second-order joint parameter uncertainty is presented in Fig. 4. Notably, most of the iterations that compare cladribine and natalizumab are in the north-east quadrant. Although most of the points are above the reference threshold of 1 GDP, $70 \%$ of them are below the $3 \times$ GDP threshold.

This distribution is coherent with the cost-effectiveness acceptability curves presented in Fig. 5, where we also present results for alemtuzumab, natalizumab, and ocrelizumab. The graph shows that cladribine has the highest probability of being cost effective when the threshold is larger than US\$47,750 per QALY gained (3 GDP per capita).

\section{Discussion}

Several new effective alternatives to treat MS have been launched in the last few years. However, many health systems struggle to provide direct access to them due to their high cost. Cladribine is one of these new drugs, which has shown to be particularly efficacious in patients with HADMS. In this study, we evaluated the cost effectiveness of cladribine compared with natalizumab (the current alternative covered in Chile), ocrelizumab, and alemtuzumab in this subset of patients, from the perspective of the Chilean health care public sector. Results indicate that cladribine can be considered cost effective only if the cost-effectiveness threshold is assumed to be equivalent to 3 GDP per capita. However, compared with ocrelizumab and alemtuzumab, cladribine is expected to be the most cost-effective alternative when they are all compared to natalizumab since ocrelizumab and alemtuzumab are dominated.

Our results are mostly consistent with similar evaluations, regardless of the differences in structural assumptions we
Fig. 2 Deterministic costeffectiveness plane for base-case results and threshold lines
Incremental cost-effectiveness plane - Base case




Fig. 3 Tornado diagram for deterministic sensitivity analyses, cladribine tablets versus natalizumab
Incremental net benefits for Cladribine vs Natalizumab using a threshold of 1 GPD per capita



Fig. 4 Cost-effectiveness plane with 10,000 Monte Carlo draws and willingness-to-pay lines for base-case results of cladribine versus natalizumab



- $\rightarrow 1 \mathrm{GPDPC} \rightarrow 3 \mathrm{GDPpC}$

GDP: Gross Domestic Product; QALY: Quality-Adjusted Life Year

have imposed into the decision model. For instance, the Canadian Agency for Drugs and Technology (CADTH) assessed cladribine, concluding that it was not a costeffective alternative in HAD-MS; a 15\% discount would be necessary to be cost effective. Thus, it was recommended for coverage only under a price reduction [30]. In contrast with Canada, cladribine was founded to be cost effective compared with all other treatments in the UK [31]. Unfortunately, we could not compare our results with NICE because they only presented SOT and RES subgroups showing differences in incremental QALYs versus alemtuzumab. Although we know that SOT and RES populations are subgroups 
Fig. 5 Multi-way cost-effectiveness acceptability curve (CEAC)

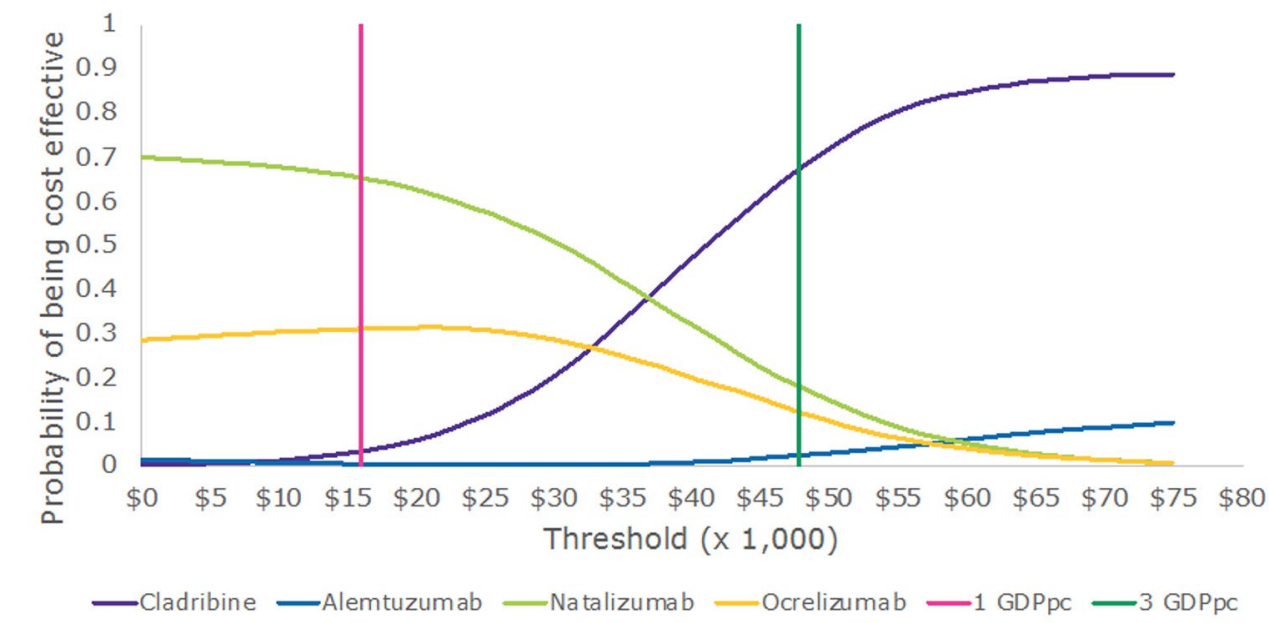

GDPpc: Gross Domestic Product per capita of HAD-MS, their effectiveness parameters are different, and despite being published by NICE, those were hidden, whereby we could not check the difference between results [12]. Furthermore, the model submitted to NICE considered a discount rate of $3.5 \%$ and a time horizon of 50 years, while our model used $3 \%$ and 45 years, respectively.

Our model considered several conservative assumptions for cladribine in the base-case scenario, such as assuming the same effectivity of cladribine as ocrelizumab due to the lack of evidence regarding the ocrelizumab treatment effect. Although it might not benefit alemtuzumab or natalizumab, a lower value than that for cladribine would not be conservative. Secondly, the model considered the same waning effect for each comparator. Besides that, cladribine has been shown to maintain its clinical effectiveness until the fourth year. However, there is not enough evidence to extrapolate this to the HAD-MS subgroup [11]. Therefore, our study considered that the declining effect begins after the second year as it is presented among other NICE appraisals and following the same strategy that NICE used for its cladribine evaluation [29, 31]. A third assumption was made in order to be conservative in terms of cost by assuming that cladribine will be administered until years 5-6, notwithstanding recent clinical trials (still to be published) suggesting this not to be necessary. Despite conservative assumptions, the results of the base-case scenario demonstrate that cladribine is the alternative with higher benefits but is not cost effective at thresholds of 3 GDP per capita. A 10\% discount over the list price of cladribine was necessary to be cost effective at 3 GDP per capita (following the WHO recommendation [32]), but not enough to be cost effective at 1 GDP per capita as suggested by the Chilean HTA guideline [23].

As was expected, the drug cost is one of the most significant drivers of the ICER. Notwithstanding, clinical effects such as disability progression could have a similar impact on the ICER. Increasing the hazard ratio of the disability progression (more risk of having a disability progression) of cladribine versus placebo by $93 \%$ suggests that cladribine is not cost effective against alemtuzumab. Likewise, when increasing the hazard ratio by $180 \%$ and $225 \%$, cladribine is not cost effective against natalizumab and ocrelizumab, respectively. Although clinical effects or utilities are essential inputs, they are not sensitive-enough parameters to vary the outcomes significantly, as can be seen in the tornado graph.

Furthermore, the estimates of the current study suggest that the incorporation of cladribine to the pool of drugs for the treatment of MS could generate additional costs for the first 2 years of therapy, but produce remarkable savings for years 3 and 4, compensating the initial expenses. Cladribine not only presented advantages in terms of QALYs gained compared with comparators, but since cladribine produces fewer relapses than the other drugs, the QALY loss avoided by this is about $70 \%$. Likewise, just by diminishing disease progression through the years, cladribine increases the QALYs gained by around $10 \%$.

One of the limitations encountered during this study was the lack of local data to estimate the real affected population in Chile. Therefore, the estimates obtained here are based on international data that could differ from the local reality. However, the positive impact regarding the budget for years 3 and 4 of treatment should behave in the same way, even though it could vary in magnitude due to the corrections made for the population of this study. Another limitation referring to the limited sources of information was the fact that for the costing in our study, we considered the use of clinical expert support, the national clinical guidelines, and prices from public health payer and public healthcare tariffs. Therefore, the cost inputs previously estimated were underestimated to compare them with better data sources such as local provider data or an annual cost resource from a hospital or health service institution, as was mentioned by Jimenez 
and Cid [33] and Gutierrez and Medina [34]. Unfortunately, those 'better sources' are not available. A third limitation regarding utility values was, firstly, these values came from CLARITY [9, 10], CLARITY EXT [11], and Hawton and Green [35], which consider the RRMS population, including HAD-MS. Using a less severe population in general terms could overestimate the utility values, increasing the QALYs gained. Nonetheless, we are aware that using foreign utility values is a limitation in cost-effectiveness analysis. However, especially for the Chilean case, utilities valued using the British tariff can be less biased than utilities valued with other tariffs. As shown by Zarate et al. [36], the national Chilean tariff is more similar to the British than the Spanish, Argentinian and American Hispanic populations.

This study presents a cost-effectiveness analysis where comparators and the population are relevant for several decision makers from Latin-American jurisdictions. Nevertheless, each of these jurisdictions should generate its own cost-effectiveness results. This study reveals the information gap that exists in Chile for MS, which means that each LatinAmerican jurisdiction should evaluate their assumptions with local experts, evaluate the possibility of using local tariffs or utilities, if appropriate, and consider the relevant comparators, such as ocrelizumab, as was the case in Chile. Our results were estimated exclusively for the Chilean case, and we suggest considering not just an appropriate price vector. Thus, our findings are not transferable to other jurisdictions and the data and the assumptions used are to be implemented exclusively in the Chilean public health system.

\section{Conclusion}

Our findings show that cladribine is the alternative with most QALYs gained; however, at a WTP threshold of 1 GDP per capita per QALY gained, it would not be a costeffective alternative to treat patients with HAD-MS in the context of the public health system of Chile. Furthermore, we were able to verify that there is a significant gap concerning data. It is essential to increase the efforts to deal with the uncertainty associated with the model. Consequently, further research on both clinical and cost parameters is required to increase the robustness of the model. Better information will also serve to deal with structural and parameter uncertainties and to support recommendations made by clinicians [37], and last but not less, to provide local data.

\section{Declarations}

Funding This study was funded by Merck S.A., Chile (a business of Merck KGaA, Darmstadt, Germany), commissioned to Pontificia Uni- versidad Católica (Santiago, Chile) under strict independence agreement.

Conflict of interest Investigators have realized this study in the context of their salary condition paid by the university and no further incentives were provided for this study. All authors declare they have received compensation from diverse pharmaceutical companies for educational services. $\mathrm{CB}$ has received honorarium from different pharmaceutical companies for educational services. ME has received compensation from diverse pharmaceutical companies for training on economic evaluation and prioritization in healthcare. $\mathrm{RR}$ has received compensation from diverse pharmaceutical companies for educational services and as a consultant.

Availability of data and material The authors confirm that the data supporting the findings of this study are available within the article.

Code availability The economic model used in this study is not publicly available by request of the local company. Any request can be coordinated by the corresponding author on reasonable request.

Author's contribution All authors contributed to the study conception and design. Material preparation, data collection, and analysis were performed by CB, MAE, RR, and AZ. The first draft of the manuscript was written by MAE and all authors commented on previous versions of the manuscript. All authors read and approved the final manuscript.

Open Access This article is licensed under a Creative Commons Attribution-NonCommercial 4.0 International License, which permits any non-commercial use, sharing, adaptation, distribution and reproduction in any medium or format, as long as you give appropriate credit to the original author(s) and the source, provide a link to the Creative Commons licence, and indicate if changes were made. The images or other third party material in this article are included in the article's Creative Commons licence, unless indicated otherwise in a credit line to the material. If material is not included in the article's Creative Commons licence and your intended use is not permitted by statutory regulation or exceeds the permitted use, you will need to obtain permission directly from the copyright holder. To view a copy of this licence, visit http://creativecommons.org/licenses/by-nc/4.0/.

\section{References}

1. Thomas RH, Wakefield RA. Oral disease-modifying therapies for relapsing-remitting multiple sclerosis. Am J Health Syst Pharm. 2015;72(1):25-38.

2. Friese MA, Schattling B, Fugger L. Mechanisms of neurodegeneration and axonal dysfunction in multiple sclerosis. Nat Rev Neurol. 2014;10(4):225-38.

3. Cristiano E, Rojas J, Romano M, Frider N, Machnicki G, Giunta D, et al. The epidemiology of multiple sclerosis in Latin America and the Caribbean: a systematic review. Mult Scler. 2013;19(7):844-54

4. Nogales-Gaete J. Esclerosis Múltiple: Una Mirada Ibero-Panamericana, 2008. Rev Chil Neuropsiquiatr. 2008;46:238-40.

5. Nogales-Gaete J, Aracena R, Cepeda-Zumaeta S, Eloiza C, Agurto $\mathrm{P}$, Díaz V, et al. Esclerosis múltiple recurrente remitente en el sector público de salud de Chile: Descripción clínica de 314 pacientes. Rev Med Chil. 2014;142:559-66.

6. Ministerio de Salud de Chile. Guía Clínica-Esclerosis Múltiple. DIPRECE, 2010. 
7. Costello K, Halper J, Kalb R, Skutnik L, Rapp R. The use of disease-modifying therapies in multiple sclerosis: Principles and Current Evidence. 2017. https://ms-coalition.org/wp-content/uploads/ 2019/06/MSC_DMTPaper_062019.pdf. Accessed January 2021

8. Montalban X, Gold R, Thompson AJ, Otero-Romero S, Amato MP, Chandraratna D, et al. ECTRIMS/EAN guideline on the pharmacological treatment of people with multiple sclerosis. Mult Scler. 2018;24(2):96-120.

9. Giovannoni G, Comi G, Cook S, Rammohan K, Rieckmann P, Sørensen PS, et al. A placebo-controlled trial of oral cladribine for relapsing multiple sclerosis. New Engl J Med. 2010;362(5):416-26.

10. Giovannoni G, Soelberg Sorensen P, Cook S, Rammohan KW, Rieckmann P, Comi G, et al. Efficacy of Cladribine Tablets in high disease activity subgroups of patients with relapsing multiple sclerosis: a post hoc analysis of the CLARITY study. Mult Scler. 2019;25(6):819-27.

11. Giovannoni G, Soelberg Sorensen P, Cook S, Rammohan K, Rieckmann P, Comi G, et al. Safety and efficacy of cladribine tablets in patients with relapsing-remitting multiple sclerosis: results from the randomized extension trial of the CLARITY study. Mult Scler. 2018;24(12):1594-604.

12. NICE. Cladribine tablets for treating relapsing-remitting multiple sclerosis (TA493). 2017.

13. Sweeney VP, Sadovnick AD, Brandejs V. Prevalence of multiple sclerosis in British Columbia. Can J Neurol Sci. 1986;13(1):47-51.

14. Tremlett H, Zhao Y, Rieckmann P, Hutchinson M. New perspectives in the natural history of multiple sclerosis. Neurology. 2010;74(24):2004-15.

15. NICE. Dimethyl fumarate for treating relapsing-remitting multiple sclerosis-technology appraisal guidance 59. 2014.

16. NICE. Fingolimod for the treatment of highly active relapsingremitting multiple sclerosis-technology appraisal guidance 254 . 2012.

17. Eddy DM, Hollingworth W, Caro JJ, Tsevat J, McDonald KM, Wong JB. Model transparency and validation: a report of the ISPOR-SMDM modeling good research practices task force-7. Med Decis Mak. 2012;32(5):733-43.

18. Rammohan K, Giovannoni G, Comi G, Cook S, Rieckmann P, Soelberg Sørensen P, et al. Cladribine tablets for relapsingremitting multiple sclerosis: efficacy across patient subgroups from the phase III CLARITY study. Mult Scler Relat Disord. 2012;1(1):49-54.

19. Pontificia Universidad Católica de Chile. Encuesta Nacional de Salud Chile 2009-2010. In: Departamento de Salud Pública, editor. 2010

20. Ministerio de Salud de Chile. Guía Clínica-Tratamiento modificador de la esclerosis múltiple remitente recurrente. In: DIPRECE, editor. 2014.

21. Ministerio de Salud de Chile. Protocolos para el otorgamiento de las prestaciones que cuentan con el Sistema de Protección Financiera para Diagnósticos y Tratamientos de Alto Costo. Ley No20.850-Esclerosis Múltiple. 2019. https://leyricartesoto.minsal.cl/\#/problemasdesalud/protocolos. Accessed January 2021

22. Siddiqui MK, Khurana IS, Budhia S, Hettle R, Harty G, Wong SL. Systematic literature review and network meta-analysis of cladribine tablets versus alternative disease-modifying treatments for relapsing-remitting multiple sclerosis. Curr Med Res Opin. 2018;34(8):1361-71.

23. Ministerio de Salud de Chile. Guía metodológica para la evaluación económica de intervenciones en salud en Chile. 2013.

24. FONASA. Arancel FONASA: Modalidad de Atención Institucional (MAI) 2018. 2019.

25. Cohen JA, Coles AJ, Arnold DL, Confavreux C, Fox EJ, Hartung HP, et al. Alemtuzumab versus interferon beta $1 \mathrm{a}$ as first-line treatment for patients with relapsing-remitting multiple sclerosis: a randomised controlled phase 3 trial. Lancet. 2012;380(9856):1819-28.

26. Polman CH, O'Connor PW, Havrdova E, Hutchinson M, Kappos L, Miller DH, et al. A randomized, placebo-controlled trial of natalizumab for relapsing multiple sclerosis. N Engl J Med. 2006;354(9):899-910.

27. Hauser SL, Bar-Or A, Comi G, Giovannoni G, Hartung H-P, Hemmer B, et al. Ocrelizumab versus interferon beta-1a in relapsing multiple sclerosis. New Engl J Med. 2016;376(3):221-34.

28. Kappos L, Li D, Calabresi PA, O'Connor P, Bar-Or A, Barkhof $\mathrm{F}$, et al. Ocrelizumab in relapsing-remitting multiple sclerosis: a phase 2, randomised, placebo-controlled, multicentre trial. Lancet. 2011;378(9805):1779-87.

29. NICE. Cladribine tablets for treating relapsing remitting multiple sclerosis [ID64]-committee paper. 2017.

30. CADTH Canadian Drug Expert Committee. Drug Reimbursement Recommendation-Cladribine. 2016.

31. NICE. Cladribine for treating relapsing-remitting multiple sclerosis 2019. https://www.nice.org.uk/guidance/ta616. Accessed January 2021

32. Bertram MY, Lauer JA, De Joncheere K, Edejer T, Hutubessy R, Kieny P, et al. Cost-effectiveness threshold: pros and cons. Bull World Health Organ. 2016;94:925-30.

33. Jiménez J, Cid C. Conocer costos en atención de salud: Una necesidad imperativa. Revista chilena de cardiología. 2011;30:227-9.

34. Gutiérrez VCG, Medina GA. Comparación de los costos reales anuales asociados al manejo ambulatorio de pacientes hipertensos del programa cardiovascular en el Hospital Comunitario de Bulnes con el pago de prestaciones de Fonasa. Revista chilena de cardiología. 2011;30:207-11.

35. Hawton A, Green C. Health utilities for multiple sclerosis. Value Health. 2016;19(4):460-8.

36. Zarate V, Kind $P$, Valenzuela $P$, Vignau A, Olivares-Tirado $P$, Munoz A. Social valuation of EQ-5D health states: the Chilean case. Value Health. 2011;14(8):1135-41.

37. Sørensen PS, Centonze D, Giovannoni G, Montalban X, Selchen D, Vermersch P, et al. Expert opinion on the use of cladribine tablets in clinical practice. Ther Adv Neurol Disord. 2020;13:1756286420935019.

38. NICE. Beta interferon and glatiramer acetate for treating multiple sclerosis (review of TA32) [ID809]—committee paper. 2017.

39. Sadovnick AD, Ebers GC, Wilson RW, Paty DW. Life expectancy in patients attending multiple sclerosis clinics. Neurology. 1992;42(5):991-4.

40. Merck. Network meta-analysis-data on file.

41. Orme M, Kerrigan J, Tyas D, Russell N, Nixon R. The effect of disease, functional status, and relapses on the utility of people with multiple sclerosis in the UK. Value Health. 2007;10(1):54-60.

42. NICE. Alemtuzumab for treating relapsing-remitting multiple sclerosis. 2014

43. Shingler S, Fordham B, Evans M, Schroeder M, Thompson G, Dewilde $S$, et al. Utilities for treatment-related adverse events in type 2 diabetes. J Med Econ. 2015;18(1):45-55.

44. Trogdon JG, Ekwueme DU, Chamiec-Case L, Guy GP Jr. Breast cancer in young women: health state utility impacts by race/ethnicity. Am J Prev Med. 2016;50(2):262-9.

45. Ministerio de Salud deChile. Evaluación Científica de la Evidencia de la Comisión de Recomendación Priorizada de la ley 20.850. 2018.

46. Ministerio de Salud de Chile. Estudio de Verificación del Costo Esperado Individual Promedio por Beneficiario del Conjunto Priorizado de Problemas de Salud con Garantías Explicitas. In: Subsecretaría de Salud Pública, editor. 2015. 